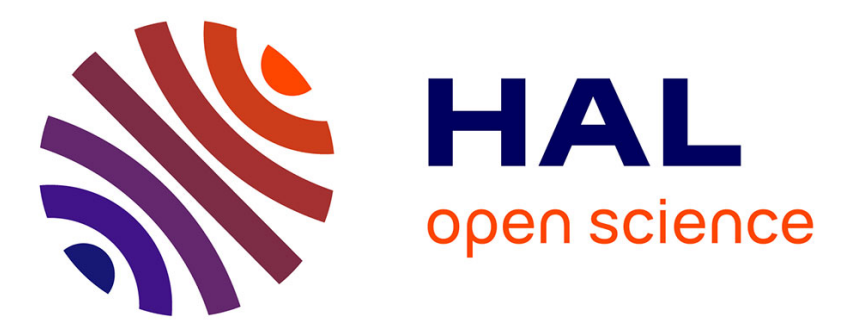

\title{
Complementary Site-Selective Sulfonylation of Aromatic Amines by Superacid Activation
}

\author{
Paul Bourbon, Emeline Appert, Agnès Martin-Mingot, Bastien Michelet, \\ Sébastien Thibaudeau
}

\section{- To cite this version:}

Paul Bourbon, Emeline Appert, Agnès Martin-Mingot, Bastien Michelet, Sébastien Thibaudeau. Complementary Site-Selective Sulfonylation of Aromatic Amines by Superacid Activation. Organic Letters, 2021, 23 (11), pp.4115-4120. 10.1021/acs.orglett.1c00994 . hal-03358394

\author{
HAL Id: hal-03358394 \\ https://hal.science/hal-03358394
}

Submitted on 29 Sep 2021

HAL is a multi-disciplinary open access archive for the deposit and dissemination of scientific research documents, whether they are published or not. The documents may come from teaching and research institutions in France or abroad, or from public or private research centers.
L'archive ouverte pluridisciplinaire HAL, est destinée au dépôt et à la diffusion de documents scientifiques de niveau recherche, publiés ou non, émanant des établissements d'enseignement et de recherche français ou étrangers, des laboratoires publics ou privés. 


\title{
Complementary Site-Selective Sulfonylation of Aromatic Amines by Superacid Activation
}

\author{
Paul Bourbon, Emeline Appert, Agnès Martin-Mingot, Bastien Michelet,* and Sébastien Thibaudeau*
}

Cite This: https://doi.org/10.1021/acs.orglett.1c00994

Read Online

\section{ACCESS | Lلlll Metrics \& More | 回 Article Recommendations | st Supporting Information}

ABSTRACT: Under superacidic conditions, aniline and indole derivatives are sulfonylated at low temperature with easy-to-access arenesulfonic acids or arenesulfonyl hydrazides. By modification of the functional-group directing effect through protonation, this method allows nonclassical site functionalization by overcoming the innate regioselectivity of electrophilic aromatic substitution. This superacid-mediated sulfonylation of arenes is complementary to existing methods and can be applied, through protection by protonation, to the late-stage site-selective functionalization of natural alkaloids and active pharmaceutical ingredients.

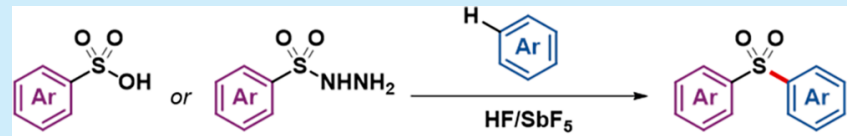

- $C$-H functionalization of inert positions $>20$ examples

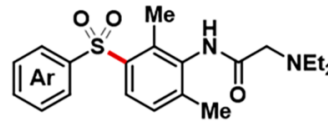

Lidocaine analogue

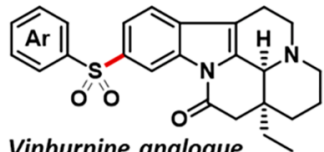

Vinburnine analogue romatic sulfones are important scaffolds in organic synthesis and have found many applications in the medicinal, agrochemical, and materials fields (Scheme 1).

Scheme 1. Selected Examples of Sulfone Derivatives and Their Applications
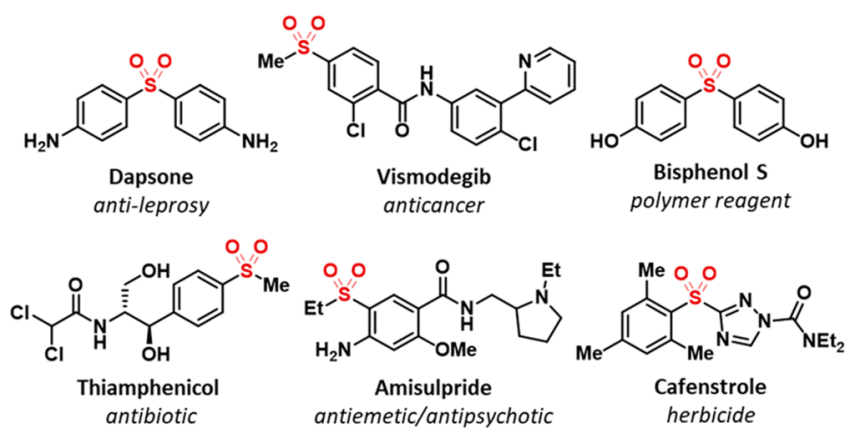

Over the past decades, numerous methods have been developed for their synthesis. ${ }^{1,2}$ The most classical approaches rely on oxidation of the corresponding sulfides or sulfoxides, addition of sulfinates to unsaturated bonds, or metal-catalyzed cross-coupling reactions from sulfinates or sulfonyl halides. ${ }^{1}$ Although these methods proved their efficiency to generate a wide variety of aromatic sulfones, they are still strongly limited by the necessity of prefunctionalizing the aromatic starting material. In this context, great efforts have recently been made to develop new methods for direct $\mathrm{C}\left(\mathrm{sp}^{2}\right)-\mathrm{H}$ sulfonylatio$\mathrm{n},^{2 \mathrm{a}-\mathrm{c}}$ mainly through metal-catalyzed $\mathrm{C}-\mathrm{H}$ activation (Scheme $2 \mathrm{a})^{3}$ or oxidative $\mathrm{C}-\mathrm{H}$ functionalization of quinolines, ${ }^{4}$ anilines, ${ }^{5}$ indoles, ${ }^{6}$ or phenol derivatives. ${ }^{7}$ However, these strategies necessitate the preinstallation of a directing group and/or are limited to specific substrates, narrowing their
Scheme 2. (a, b) Reported Methods for Direct $\mathrm{C}-\mathrm{H}$ Sulfonylation of Arenes and (c) Our Strategy Using Superacid Activation

a. Directed C-H activation (ref. 2c, 3, 8)

$$
\text { Metal }
$$

Metal $=\mathrm{Pd}, \mathrm{Rh}, \mathrm{Ru}, \mathrm{Ni}, \mathrm{Cu}$

$\mathrm{RSO}_{2} \mathrm{Y}=\mathrm{RSO}_{2} \mathrm{Cl}, \mathrm{RSO}_{2} \mathrm{Na}, \mathrm{ArN}_{2}{ }^{+} / \mathrm{DABCO} \cdot\left(\mathrm{SO}_{2}\right)_{2}$

b. Friedel-Crafts-type sulfonylation (ref. 9)

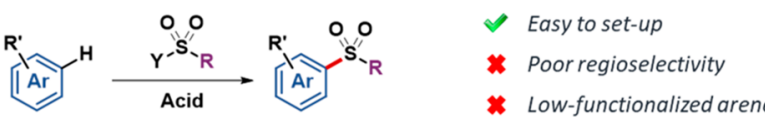

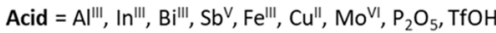
$\mathrm{RSO}_{2} \mathrm{Y}=\mathrm{RSO}_{3} \mathrm{H}, \mathrm{RSO}_{2} \mathrm{X}, \mathrm{RSO}_{2} \mathrm{OTf}, \mathrm{RSO}_{2} \mathrm{NHTf} \mathrm{RSO}_{2} \mathrm{~N}_{3}$ $\mathbf{R}^{\prime}=\mathrm{H}, \mathrm{Me}, \mathrm{OMe}, \mathrm{X}$

c. Superacid-mediated aromatic sulfonylation (this work)

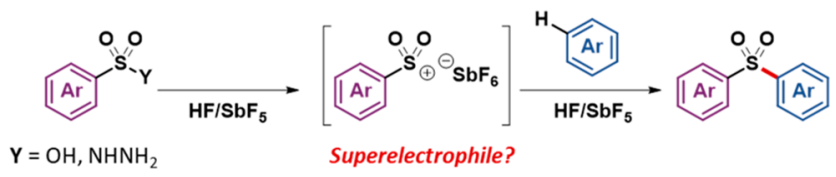

Received: March 23, 2021 
scope of application. Moreover, although it is highly sitespecific, directed $\mathrm{C}-\mathrm{H}$ sulfonylation of arenes occurs mostly at the position ortho to the directing group. ${ }^{2 c, 8}$ On the other hand, one of the simplest and oldest strategies to substitute an aromatic hydrogen atom by a sulfonyl group is probably aromatic electrophilic substitution, akin to Friedel-Crafts acylation (Scheme 2b). 9 This strategy benefits from ease of setup, a large variety of accessible catalysts, and a wide range of commercially available reagents. Nevertheless, in most cases Friedel-Crafts-type sulfonylation is applicable only to lowweight benzene derivatives and suffers from poor regioselectivity dictated by the innate orientation effect of the substituents.

We previously demonstrated ${ }^{10}$ that under superacid conditions, $^{11}$ aromatic amines (or amides)-despite being fully protonated-can react with an electrophile provided that the latter is further activated by the superacidic medium (superelectrophilic activation). ${ }^{12}$ In particular, under these conditions the orientation effect of the amine substituent is no longer effective, and the site selectivity of the reaction is dictated by the secondary substituent, leading to nonclassical regioselectivity. Motivated by these previous results and by the absence of general procedures for direct electrophilic sulfonylation of aromatic amines, ${ }^{9}$ we aimed at developing a complementary site-selective method that would allow the direct functionalization of aniline and indole derivatives from readily available sulfone precursors by taking advantage of superelectrophilic activation (Scheme 2c).

We started our investigations with $p$-methylacetanilide as model substrate and benzenesulfonic acid $\mathbf{A}_{\mathbf{a}}$ as a cheap and readily available sulfonyl source (Table 1 ). With neat $\mathrm{HF} / \mathrm{SbF}_{5}$ (7/1) superacid, the desired product $1 \mathrm{a}$ was obtained after $2 \mathrm{~h}$ at $-20{ }^{\circ} \mathrm{C}$ in an encouraging $30 \%$ yield (Table 1 , entry 1 ). Delightfully, the substrate was selectively functionalized at the meta position (with respect to the acetamido group), confirming our initial hypothesis. The peculiar regioselectivity of this transformation was also confirmed by X-ray analysis of collected crystals of 1a (see the Supporting Information (SI)). We next evaluated the impact of the acidity on the reactivity by modulating the concentration of $\mathrm{SbF}_{5}$ (Table 1, entries 1-4) and found that the optimal conditions were reached with a 2/1 $\mathrm{HF} / \mathrm{SbF}_{5}$ mixture (73\% yield; Table 1 , entry 3 ). Increasing the amount of benzenesulfonic acid to 2 equiv did not improve the yield (Table 1 , entry 5 ). While decreasing the temperature to $-40{ }^{\circ} \mathrm{C}$ completely inhibited the reaction (Table 1 , entry 6 ), performing the reaction at higher temperature led to a poor yield and to the formation of the undesired regioisomer $1 \mathbf{a}^{\prime}$ (Table 1, entry 7). The formation of $\mathbf{1} \mathbf{a}^{\prime}$ can be explained by an initial intramolecular rearrangement within the arenium ion generated by the protonation of $p$-methylacetanilide to the more stable $m$-methylacetanilide, which then reacts with benzenesulfonic acid. ${ }^{13,14}$ No reaction occurred using the weaker superacid $\mathrm{TfOH}$ (Table 1, entry 8), a result that supports our initial hypothesis and the necessity to use superelectrophilic activation to perform this transformation. As expected, the use of excess of Lewis acids in dichloromethane did not afford the desired product even at room temperature with a prolonged reaction time (Table 1, entries 9-14). We next evaluated the reactivity of $p$-methylacetanilide with other sulfonyl precursors (Table 1, entries 15-23). Methyl sulfonate $\mathbf{B}_{\mathbf{a}}$ was found to be totally unreactive under these conditions (Table 1, entry 15). Although good conversion of the starting material was obtained with sulfonyl chloride $\mathbf{C}_{a}$, $\mathbf{1 a}$ was
Table 1. Optimization of the Superacid-Promoted Benzenesulfonylation of $\boldsymbol{p}$-Methylacetanilide

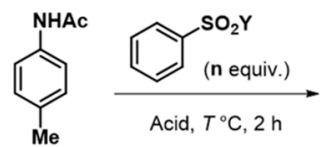

Benzenesulfonyl sources:

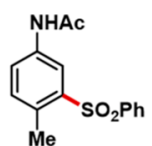

1a

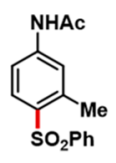

$1 a^{\prime}$

\begin{tabular}{|c|c|c|c|c|c|}
\hline \multirow[b]{2}{*}{ entry } & \multirow[b]{2}{*}{$\operatorname{acid}(\mathrm{v} / \mathrm{v})^{a}$} & \multirow[b]{2}{*}{$\mathrm{PhSO}_{2} \mathrm{Y}(n)$} & \multirow[b]{2}{*}{$T\left[{ }^{\circ} \mathrm{C}\right]$} & \multicolumn{2}{|c|}{ Yield $[\%]^{b}$} \\
\hline & & & & 1a & $1 a^{\prime}$ \\
\hline 1 & $\mathrm{HF} / \mathrm{SbF}_{5}(7 / 1)$ & $\mathbf{A}_{\mathrm{a}}(1.2)$ & -20 & 30 & 0 \\
\hline 2 & $\mathrm{HF} / \mathrm{SbF}_{5}(3 / 1)$ & $A_{a}(1.2)$ & -20 & 58 & 0 \\
\hline 3 & $\mathrm{HF} / \mathrm{SbF}_{5}(2 / 1)$ & $A_{a}(1.2)$ & -20 & $73^{c}$ & $\mathbf{0}$ \\
\hline 4 & $\mathrm{HF} / \mathrm{SbF}_{5}(1 / 1)$ & $\mathbf{A}_{\mathrm{a}}(1.2)$ & -20 & 49 & 0 \\
\hline 5 & $\mathrm{HF} / \mathrm{SbF}_{5}(2 / 1)$ & $A_{a}(2.0)$ & -20 & 72 & 0 \\
\hline 6 & $\mathrm{HF} / \mathrm{SbF}_{5}(2 / 1)$ & $\mathbf{A}_{\mathrm{a}}(1.2)$ & -40 & 0 & 0 \\
\hline 7 & $\mathrm{HF} / \mathrm{SbF}_{5}(2 / 1)$ & $\mathbf{A}_{\mathrm{a}}(1.2)$ & 0 & 15 & 45 \\
\hline 8 & $\mathrm{TfOH}$ & $\mathbf{A}_{\mathrm{a}}(1.2)$ & -20 & 0 & 0 \\
\hline $9^{d}$ & $\mathrm{SbF}_{5}{ }^{e}$ & $\mathrm{~A}_{\mathrm{a}}(1.2)$ & 20 & 0 & 0 \\
\hline $10^{d}$ & $\mathrm{AlCl}_{3}^{e}$ & $\mathrm{~A}_{\mathrm{a}}(1.2)$ & 20 & 0 & 0 \\
\hline $11^{d}$ & $\mathrm{FeCl}_{3}^{e}$ & $\mathbf{A}_{\mathrm{a}}(1.2)$ & 20 & 0 & 0 \\
\hline $12^{d}$ & $\mathrm{Cu}(\mathrm{OTf})_{2}^{e}$ & $\mathbf{A}_{\mathrm{a}}(1.2)$ & 20 & 0 & 0 \\
\hline $13^{d}$ & $\mathrm{Bi}(\mathrm{OTf})_{3}^{e}$ & $\mathbf{A}_{\mathrm{a}}(1.2)$ & 20 & 0 & 0 \\
\hline $14^{d}$ & $\mathrm{P}_{2} \mathrm{O}_{5}^{e}$ & $\mathbf{A}_{\mathrm{a}}(1.2)$ & 20 & 0 & 0 \\
\hline 15 & $\mathrm{HF} / \mathrm{SbF}_{5}(2 / 1)$ & $\mathrm{B}_{\mathrm{a}}(1.2)$ & -20 & 0 & 0 \\
\hline 16 & $\mathrm{HF} / \mathrm{SbF}_{5}(2 / 1)$ & $\mathrm{C}_{\mathrm{a}}(1.2)$ & -20 & $10^{f}$ & 0 \\
\hline 17 & $\mathrm{HF} / \mathrm{SbF}_{5}(2 / 1)$ & $\mathrm{D}_{\mathrm{a}}(1.2)$ & -20 & 12 & 0 \\
\hline 18 & $\mathrm{HF} / \mathrm{SbF}_{5}(2 / 1)$ & $\mathrm{E}_{\mathrm{a}}(1.2)$ & -20 & 0 & 0 \\
\hline 19 & $\mathrm{HF} / \mathrm{SbF}_{5}(2 / 1)$ & $\mathbf{F}_{\mathbf{a}}(1.2)$ & -20 & 0 & 0 \\
\hline 20 & $\mathrm{HF} / \mathrm{SbF}_{5}(2 / 1)$ & $\mathrm{G}_{\mathrm{a}}(1.2)$ & -20 & 68 & 0 \\
\hline 21 & $\mathrm{HF} / \mathrm{SbF}_{5}(2 / 1)$ & $\mathbf{H}_{\mathrm{a}}(1.2)$ & -20 & 3 & 0 \\
\hline 22 & $\mathrm{HF} / \mathrm{SbF}_{5}(2 / 1)$ & $\mathbf{I}_{\mathrm{a}}(1.2)$ & -20 & 86 & 0 \\
\hline 23 & $\mathrm{HF} / \mathrm{SbF}_{5}(2 / 1)$ & $\mathrm{J}_{\mathrm{a}}(1.2)$ & -20 & 72 & $\mathbf{0}$ \\
\hline
\end{tabular}

${ }^{a}$ Used as the solvent unless stated otherwise. ${ }^{b}$ Yields of isolated products. ${ }^{c} 58 \%$ yield after $1 \mathrm{~h} .{ }^{d}$ The reaction time was extended to 20 h. ${ }^{e} 2$ equiv in $\mathrm{CH}_{2} \mathrm{Cl}_{2}$. ${ }^{f}$ Concomitant formation of 3-chloro-4methylacetanilide in $50 \%$ yield.

obtained in a low $10 \%$ yield accompanied by the formation of 3 -chloro-4-methylacetanilide in 50\% yield (Table 1 , entry 16 ). In this case, reagent $\mathbf{C}$ is a source of chloride ions, which can be oxidized in situ by $\mathrm{Sb}^{\mathrm{V}}$. The generated halenium ions then react with the aromatic nucleophile to furnish the chlorinated product, as previously observed. ${ }^{10 \mathrm{~b}}$ In order to avoid this competitive process, sulfonyl fluoride $\mathbf{D}_{\mathbf{a}}$ was evaluated as the reaction partner (Table 1 , entry 17). ${ }^{15}$ However, the reaction was very slow in this case, and 1a was isolated in only $12 \%$ yield. We next turned our attention to sulfonyl reagents derived from sulfonamide. While $N, N$-dimethylsulfonamide $\mathbf{E}_{\mathbf{a}}$ and $N$-acetylsulfonamide $\mathbf{F}_{\mathbf{a}}$ were found to be unreactive (Table 1, entries 18 and 19), using the symmetrical sulfonimide $\mathbf{G}_{\mathbf{a}}$ afforded $\mathbf{1 a}$ in a good $68 \%$ yield (Table 1, entry 20). On the other hand, only traces of 1 a were obtained when the reaction was performed with imidazole derivative $\mathbf{H}_{\mathbf{a}}$ (Table 1, entry 21). Sulfonyl azide $\mathbf{I}_{\mathbf{a}}$ and sulfonyl hydrazide $\mathbf{J}_{\mathbf{a}}$ were revealed to be also very efficient in this transformation, broadening the panel of reagents with the ability to sulfonate aromatic amines in superacid. Under these conditions, 1a was 
obtained in $86 \%$ and $72 \%$ yield from $\mathbf{I}_{\mathbf{a}}$ and $\mathbf{J}_{\boldsymbol{a}}$, respectively (Table 1, entries 22 and 23).

With these optimized conditions in hand, we next moved to the study of the scope and limitations of this transformation, starting with the screening of various arenesulfonyl precursors (Scheme 3). At this stage, we decided to evaluate the reactivity

Scheme 3. Scope and Limitations of the SuperacidPromoted Sulfonylation of $p$-Methylacetanilide Using Various Sulfonylation Reagents
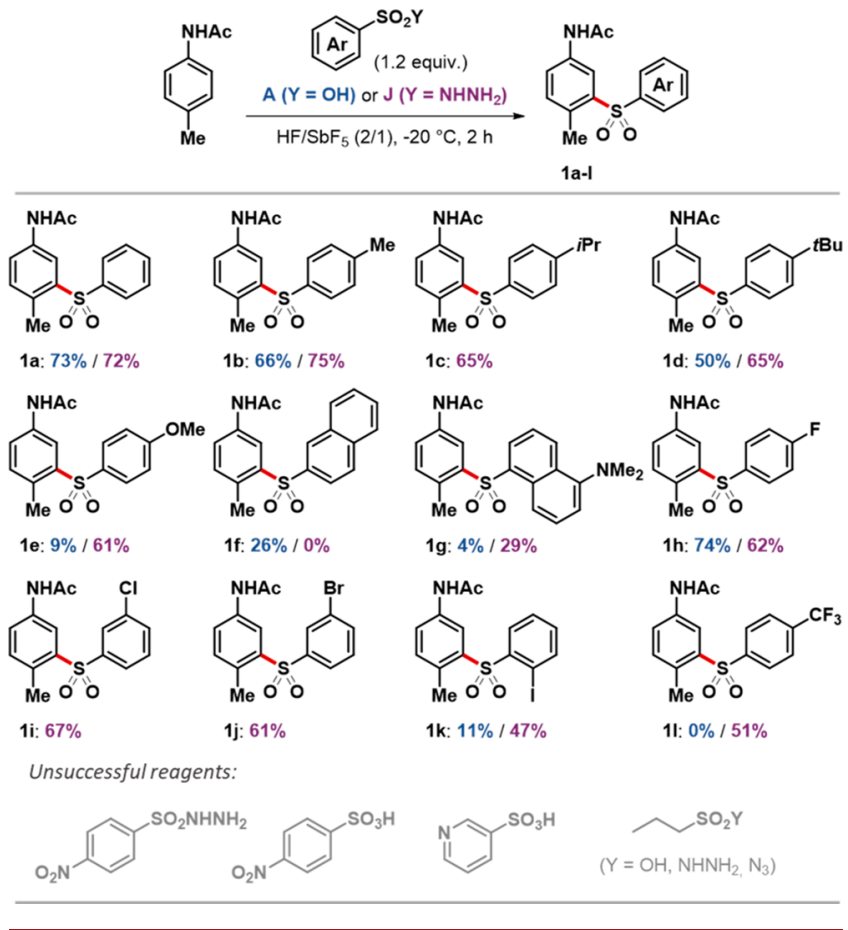

of both sulfonic acids and sulfonyl hydrazides. We chose to discard G-type sulfonimides (as they would be less accessible once functionalized) and sulfonyl azides (for safety reasons). It appeared that sulfonic acids, despite their apparent simplicity, are not ideal reagents: they are surprisingly less commercially available than the sulfonyl chloride analogues (from which they were prepared in some cases), sometimes difficult to synthesize, and most of all highly hygroscopic, leading to poorly reproducible results. On the contrary, sulfonyl hydrazides $^{2 \mathrm{~d}}$ are easy-to-handle, are readily prepared from the corresponding sulfonyl chlorides and hydrazine hydrate, and gave better results than their sulfonic acid counterparts in most of the cases. Thus, diaryl sulfones $\mathbf{1 a}-\mathbf{d}$ were synthesized from alkyl-substituted arenesulfonyl precursors in good yields with, again, full meta selectivity. The reaction proceeded equally well with an electron-rich methoxy-substituted arenesulfonyl hydrazide, affording compound 1e in $61 \%$ yield. Naphthalene derivatives $\mathbf{1 f}$ and $\mathbf{1 g}$ could also be generated, although in low yields due to the extensive formation of degradation byproducts. Halo-substituted arenesulfonyl hydrazides were also compatible with these conditions, affording fluoro-, chloro-, bromo-, and iodo-substituted diaryl sulfones $\mathbf{1 h}-\mathbf{k}$. This method also afforded diaryl sulfone $\mathbf{1 l}$ from an electron-poor trifluoromethyl-substituted arenesulfonyl hydrazide. However, strongly deactivated arenesulfonyl precursors, such as nosyl or 3-pyridinesulfonyl derivatives, and alkanesulfonyl reagents were found to be unreactive under these conditions.

We next evaluated the scope of the superacid-mediated sulfonylation on various aromatic amines (Scheme 4). With $p$ -

Scheme 4. Scope of the Superacid-Promoted Sulfonylation of Arenes Using Reagent $\mathrm{J}_{\mathrm{h}}$

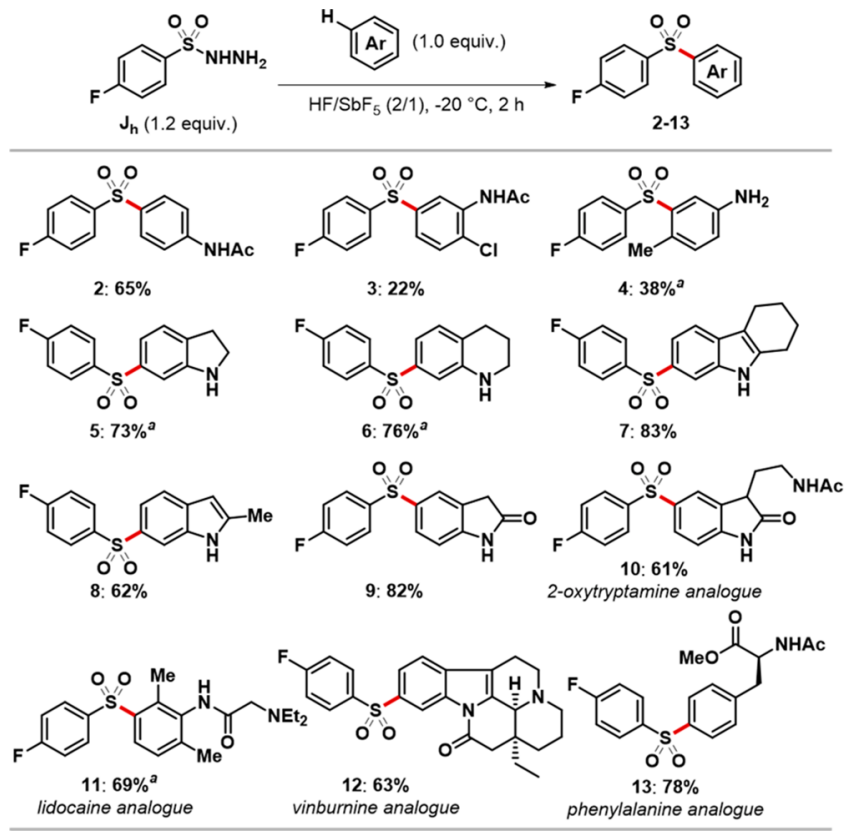

${ }^{a}$ The reaction time was extended to $4 \mathrm{~h}$, and 2.4 equiv of $\mathrm{J}_{\mathrm{h}}$ was used.

fluorobenzenesulfonyl hydrazide $\mathbf{J}_{\mathbf{h}}$, unsubstituted acetanilide reacted as expected at the para position, affording sulfone $\mathbf{2}$ in $65 \%$ yield. The meta-sulfonylation was again observed starting from 2-chloroacetanilide to afford compound 3, the chloro substituent orientating the substitution in this case despite its innate deactivating nature. The reaction could also be performed on unprotected 4-methylaniline to afford product 4, albeit with moderate efficiency. On the other hand, the sulfonylation was found very efficient on unprotected indoline, tetrahydroquinoline, and tetrahydrocarbazole, affording the corresponding compounds 5-7 in very good yields. In all three cases, the reaction occurred meta to the nitrogen atom and para to the alkyl chain. The unnatural regioselectivity of this reaction is even more striking with 2-methylindole as the starting material. Indoles are known to be excellent nucleophiles, usually reacting at $\mathrm{C} 3 .^{16}$ In our case, the C6sulfonylated compound $\mathbf{8}$ was exclusively obtained and represents, to the best of our knowledge, the first example of non-directed $\mathrm{C}-\mathrm{H}$ sulfonylation at $\mathrm{C} 6$ from a $\mathrm{C} 3$-unsubstituted indole. $^{3 \mathrm{~b}}$ This unusual selectivity for an electrophilic substitution on indole derivatives can be attributed to the formation of an iminium ion after protonation of the pyrrole ring in superacid. Oxindoles tend to react at C5, as exemplified by the preparation of sulfones $\mathbf{9}$ and $\mathbf{1 0}$ in good to very good yields. This superacid-mediated sulfonylation could also be applied to the late-stage functionalization of more complex and valuable substrates. The local anesthetic lidocaine was efficiently sulfonylated at C3 to furnish compound 11. The vinca alkaloid vinburnine was functionalized at $\mathrm{C} 6$ of its indole core to give $\mathbf{1 2}$ in good yield. Protected phenylalanine was also 
found to be compatible with our conditions and was transformed into optically pure sulfone $\mathbf{1 3}$ in very good yield. ${ }^{17}$

To gain better insight into the mechanism of this transformation and explore the transient formation of an activated sulfonyl intermediate, we next decided to evaluate the behavior of benzenesulfonic acid $\mathrm{A}_{\mathrm{a}}$ in $\mathrm{HF} / \mathrm{SbF}_{5}$ by lowtemperature in situ NMR analysis (see the SI). The ${ }^{1} \mathrm{H}$ NMR spectrum of this mixture displayed two sets of signals corresponding to two different species in a 4.6 to 1 ratio. Interestingly, in the ${ }^{19} \mathrm{~F}$ NMR spectrum, a new signal appeared at $58.0 \mathrm{ppm}$ that was attributed to the formation of a sulfonyl fluoride derivative, as previously observed by Olah under similar conditions. ${ }^{18}$ This was confirmed by the NMR analysis of a solution of benzenesulfonyl fluoride $\mathrm{D}_{\mathrm{a}}$ in $\mathrm{HF} / \mathrm{SbF}_{5}$, which provided the same set of ${ }^{1} \mathrm{H}$ NMR signals as for the major species observed from benzenesulfonic acid $\mathbf{A}_{\mathrm{a}}$. The formation of the sulfonyl fluoride was also confirmed by ${ }^{19} \mathrm{~F}$ and ${ }^{13} \mathrm{C}$ NMR analyses. We also submitted reagent $\mathbf{A}_{\mathbf{a}}$ to the softer superacid $\mathrm{TfOH}$ and obtained a very clean ${ }^{1} \mathrm{H}$ NMR spectrum displaying the same signals as for the minor species observed in $\mathrm{HF} / \mathrm{SbF}_{5}$. More importantly, no evidence for the eventual addition of triflate to benzenesulfonic acid was obtained, despite the stronger nucleophilicity of triflate anion compared with fluoroantimonates. ${ }^{19}$ This observation suggests that under $\mathrm{HF} / \mathrm{SbF}_{5}$ conditions, benzenesulfonic acid is transformed into a highly activated electrophilic species. Although this species could not be directly observed because of its rapid transformation into sulfonyl fluoride, we can postulate the formation of a benzenesulfonylium ion, as has been previously suggested. ${ }^{18}$ In the presence of an aromatic nucleophile, the transient generation of this key intermediate would trigger the electrophilic aromatic substitution (Scheme 5, path a), while in

Scheme 5. Postulated Mechanism of the Superacid-

Promoted C-H Sulfonylation of Arenes from Sulfonic Acids and Hydrazides

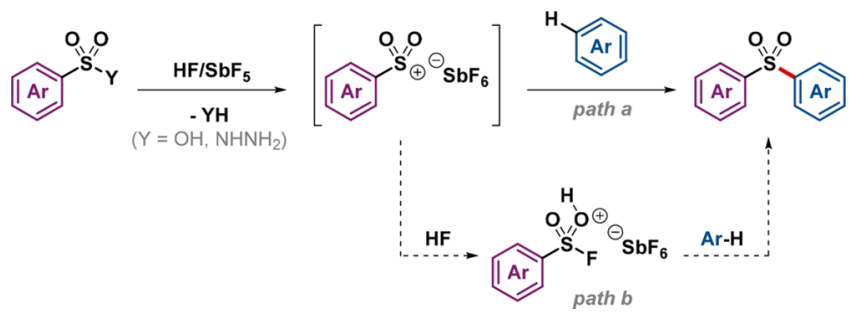

the absence of a sufficiently nucleophilic partner, the latter sulfonylium ion would collapse to the more stable sulfonyl fluoride, ${ }^{20,21}$ which would react very slowly because of its very high stability in superacidic media ${ }^{21}$ (Scheme 5, path b).

To confirm the generality of this mechanistic hypothesis, we evaluated the reactivity of the benzenesulfonyl sources listed in Table 1 by in situ NMR analysis in $\mathrm{HF} / \mathrm{SbF}_{5}$ without nucleophilic partners (see the SI). As expected, the effective reagents $\mathbf{C}_{a}, \mathbf{G}_{a}, \mathbf{I}_{a}$ and $\mathbf{J}_{\mathrm{a}}$ were almost instantaneously transformed into sulfonyl fluoride similarly to $\mathbf{A}_{a}$, while the ineffective sulfonyl derivatives remained stable or were transformed very slowly. Likewise, the low reactivity of alkanesulfonic acids under these conditions could be explained by the very high stability of their protonated forms in superacid. $^{18}$

To conclude, taking advantage of the superelectrophilic activation of simple arenesulfonic acids and hydrazides, we have developed a direct and regioselective $\mathrm{C}-\mathrm{H}$ sulfonylation of arenes at low temperature. These conditions allow the electrophilic sulfonylation of functionalized arenes with excellent regioselectivity. Furthermore, aniline and indole derivatives are functionalized with nonclassical regioselectivity due to deactivation of their nitrogen substituent by protonation. In a context where new approaches are required to address unmet selectivity challenges in the field of late-stage $\mathrm{C}-\mathrm{H}$ functionalization, ${ }^{22}$ this new method provides access to diaryl sulfones with site selectivity complementary to that of existing methods.

\section{ASSOCIATED CONTENT}

\section{Supporting Information}

The Supporting Information is available free of charge at https://pubs.acs.org/doi/10.1021/acs.orglett.1c00994.

General experimental procedures, reaction setup, characterization data, low-temperature NMR spectra, and spectra for all key compounds (PDF)

\section{Accession Codes}

CCDC 2081182 contains the supplementary crystallographic data for this paper. These data can be obtained free of charge via www.ccdc.cam.ac.uk/data request/cif, or by emailing data_request@ccdc.cam.ac.uk, or by contacting The Cambridge Crystallographic Data Centre, 12 Union Road, Cambridge CB2 1EZ, U.K.; fax: +44 1223336033

\section{AUTHOR INFORMATION}

\section{Corresponding Authors}

Sébastien Thibaudeau - Université de Poitiers, UMR-CNRS 7285, IC2MP, Superacid Lab - Organic Synthesis Team, 86073 Poitiers, France; (ㅇ orcid.org/0000-0002-62465829; Email: sebastien.thibaudeau@univ-poitiers.fr

Bastien Michelet - Université de Poitiers, UMR-CNRS 7285, IC2MP, Superacid Lab - Organic Synthesis Team, 86073

Poitiers, France; Email: bastien.michelet@univ-poitiers.fr

\section{Authors}

Paul Bourbon - Université de Poitiers, UMR-CNRS 7285, IC2MP, Superacid Lab - Organic Synthesis Team, 86073 Poitiers, France

Emeline Appert - Université de Poitiers, UMR-CNRS 7285, IC2MP, Superacid Lab - Organic Synthesis Team, 86073 Poitiers,France; @rtMolecule, 86000 Poitiers, France

Agnès Martin-Mingot - Université de Poitiers, UMR-CNRS 7285, IC2MP, Superacid Lab - Organic Synthesis Team, 86073 Poitiers, France

Complete contact information is available at: https://pubs.acs.org/10.1021/acs.orglett.1c00994

\section{Notes}

The authors declare no competing financial interest.

\section{ACKNOWLEDGMENTS}

We gratefully acknowledge the Région Nouvelle-Aquitaine (Ph.D. grant to P.B.), ANRT and the @rtMolecule Society (Ph.D. grant to E.A. and financial support through the ISOTOP Project). We also acknowledge the University of Poitiers, the Centre National de la Recherche Scientifique 
(CNRS), the European Union (ERDF), and the French Fluorine Network (GIS-FLUOR).

\section{REFERENCES}

(1) For a comprehensive review, see: Liu, N.-W.; Liang, S.; Manolikakes, G. Recent Advances in the Synthesis of Sulfones. Synthesis 2016, 48, 1939-1973 and references therein.

(2) For other relevant reviews of the synthesis of sulfones, see: (a) Shaaban, S.; Liang, S.; Liu, N.-W.; Manolikakes, G. Synthesis of Sulfones via Selective $\mathrm{C}-\mathrm{H}$-functionalization. Org. Biomol. Chem. 2017, 15, 1947-1955. (b) Qiu, G.; Zhou, K.; Wu, J. Recent Advances in the Sulfonylation of $\mathrm{C}-\mathrm{H}$ Bonds with the Insertion of Sulfur Dioxide. Chem. Commun. 2018, 54, 12561-12569. (c) Liu, J.; Zheng, L. Recent Advances in Transition-Metal-Mediated Chelation-Assisted Sulfonylation of Unactivated C-H Bonds. Adv. Synth. Catal. 2019, 361, 1710-1732. (d) Zhao, S.; Chen, K.; Zhang, L.; Yang, W.; Huang, D. Sulfonyl Hydrazides in Organic Synthesis: A Review of Recent Studies. Adv. Synth. Catal. 2020, 362, 3516-3541. (e) Joseph, D.; Idris, M. A.; Chen, J.; Lee, S. Recent Advances in the Catalytic Synthesis of Arylsulfonyl Compounds. ACS Catal. 2021, 11, 41694204.

(3) For recent examples, see: (a) Liu, T.; Zhou, W.; Wu, J. Palladium-Catalyzed Direct C-H Functionalization of Indoles with the Insertion of Sulfur Dioxide: Synthesis of 2-Sulfonated Indoles. Org. Lett. 2017, 19, 6638-6641. (b) Karmakar, U.; Samanta, R. $\mathrm{Pd}(\mathrm{II})-$ Catalyzed Direct Sulfonylation of Benzylamines Using Sodium Sulfinates. J. Org. Chem. 2019, 84, 2850-2861. (c) Zhi, C.; Wang, Q.; Liu, S.; Xue, Y.; Shi, L.; Zhu, X.; Hao, X.-Q.; Song, M.-P. CuCatalyzed Direct C7 Sulfonylation of Indolines with Arylsulfonyl Chlorides. J. Org. Chem. 2020, 85, 1022-1032.

(4) For recent examples, see: (a) Wei, J.; Jiang, J.; Xiao, X.; Lin, D.; Deng, Y.; Ke, Z.; Jiang, H.; Zeng, W. Copper-Catalyzed Regioselective $\mathrm{C}-\mathrm{H}$ Sulfonylation of 8-Aminoquinolines. J. Org. Chem. 2016, 81, 946-955. (b) Wang, K.; Wang, G.; Duan, G.; Xia, C. Cobalt(II)catalyzed Remote C5-selective C-H Sulfonylation of Quinolines via Insertion of Sulfur Dioxide. RSC Adv. 2017, 7, 51313-51317. (c) Jiang, M.; Yuan, Y.; Wang, T.; Xiong, Y.; Li, J.; Guo, H.; Lei, A. Exogenous-oxidant- and Catalyst-free Electrochemical Deoxygenative C2 Sulfonylation of Quinoline N-oxides. Chem. Commun. 2019, 55, 13852-13855.

(5) For recent examples, see: (a) Zhou, K.; Zhang, J.; Lai, L.; Cheng, J.; Sun, J.; Wu, J. C-H. Bond Sulfonylation of Anilines with the Insertion of Sulfur Dioxide under Metal-free Conditions. Chem. Commun. 2018, 54, 7459-7462. (b) Johnson, T. C.; Elbert, B. L.; Farley, A. J. M.; Gorman, T. W.; Genicot, C.; Lallemand, B.; Pasau, P.; Flasz, J.; Castro, J. L.; MacCoss, M.; Dixon, D. J.; Paton, R. S.; Schofield, C. J.; Smith, M. D.; Willis, M. C. Direct Sulfonylation of Anilines Mediated by Visible Light. Chem. Sci. 2018, 9, 629-633. (c) Wu, Y.-C.; Jiang, S.-S.; Luo, S.-Z.; Song, R.-J.; Li, J.-H. Transitionmetal- and Oxidant-free Directed Anodic C-H Sulfonylation of $\mathrm{N}, \mathrm{N}$ disubstituted Anilines with Sulfinates. Chem. Commun. 2019, 55, 8995-8998.

(6) For recent examples, see: (a) Xiao, F.; Chen, H.; Xie, H.; Chen, S.; Yang, L.; Deng, G.-J. Iodine-Catalyzed Regioselective 2Sulfonylation of Indoles with Sodium Sulfinates. Org. Lett. 2014, 16, 50-53. (b) Yang, Y.; Li, W.; Xia, C.; Ying, B.; Shen, C.; Zhang, P. Catalyst-Controlled Selectivity in $\mathrm{C}-\mathrm{S}$ Bond Formation: Highly Efficient Synthesis of C2- and C3-Sulfonylindoles. ChemCatChem 2016, 8, 304-307.

(7) For recent examples, see: (a) Liang, S.; Ren, Y.; Manolikakes, G. Manganese(III) Acetate Mediated C-H Sulfonylation of 1,4Dimethoxybenzenes with Sodium and Lithium Sulfinates. Eur. J. Org. Chem. 2017, 2017, 4117-4120. (b) Zhou, K.; Chen, M.; Yao, L.; $\mathrm{Wu}, \mathrm{J}$. Synthesis of Sulfonated Naphthols via $\mathrm{C}-\mathrm{H}$ Bond Functionalization with the Insertion of Sulfur Dioxide. Org. Chem. Front. 2018, 5, 371-375. (c) Halder, P.; Humne, V. T.; Mhaske, S. B. Transition-Metal-Free Regioselective One-Pot Synthesis of Aryl Sulfones from Sodium Sulfinates via Quinone Imine Ketal. J. Org. Chem. 2019, 84, 1372-1378.
(8) For rare examples of meta-sulfonylation, see: (a) Saidi, O.; Marafie, J.; Ledger, A. E. W.; Liu, P. M.; Mahon, M. F.; Kociok-Köhn, G.; Whittlesey, M. K.; Frost, C. G. Ruthenium-Catalyzed Meta Sulfonation of 2-Phenylpyridines. J. Am. Chem. Soc. 2011, 133, 19298-19301. (b) Li, G.; Lv, X.; Guo, K.; Wang, Y.; Yang, S.; Yu, L.; $\mathrm{Yu}, \mathrm{Y}$.; Wang, J. Ruthenium-catalyzed meta-selective $\mathrm{C}-\mathrm{H}$ sulfonation of azoarenes with arylsulfonyl chlorides. Org. Chem. Front. 2017, 4, 1145-1148. (c) Li, G.; Zhu, B.; Ma, X.; Jia, C.; Lv, X.; Wang, J.; Zhao, F.; Lv, Y.; Yang, S. Ruthenium-Catalyzed ortho/meta-Selective Dual C-H Bonds Functionalizations of Arenes. Org. Lett. 2017, 19, $5166-5169$

(9) For representative examples, see: (a) Olah, G. A.; Kobayashi, S.; Nishimura, J. Friedel-Crafts Sulfonylation of Benzene and Toluene with Alkyl- and Arylsulfonyl Halides and Anhydrides. J. Am. Chem. Soc. 1973, 95, 564-569. (b) Ueda, M.; Uchiyama, K.; Kano, T. A New Synthesis of Diaryl Sulfones. Synthesis 1984, 1984, 323-325. (c) Hyatt, J. A.; White, A. W. Synthesis of Aryl Alkyl and Aryl Vinyl Sulfones via Friedel-Crafts Reactions of Sulfonyl Fluorides. Synthesis 1984, 1984, 214-217. (d) Repichet, S.; Le Roux, C.; Hernandez, P.; Dubac, J.; Desmurs, J.-R. Bismuth(III) Trifluoromethanesulfonate: An Efficient Catalyst for the Sulfonylation of Arenes. J. Org. Chem. 1999, 64, 6479-6482. (e) Singh, R. P.; Kamble, R. M.; Chandra, K. L.; Saravanan, P.; Singh, V. K. An Efficient Method for Aromatic Friedel-Crafts Alkylation, Acylation, Benzoylation, and Sulfonylation Reactions. Tetrahedron 2001, 57, 241-247. (f) Frost, C. G.; Hartley, J. P.; Whittle, A. J. Indium-Catalysed Aryl and Alkyl Sulfonylation of Aromatics. Synlett 2001, 2001, 830-832. (g) Olah, G. A.; Mathew, T.; Surya Prakash, G. K. Nafion-H Catalysed Sulfonylation of Aromatics with Arene/Alkenesulfonic Acids for the Preparation of Sulfones. Chem. Commun. 2001, 17, 1696-1697. (h) Alizadeh, A.; Khodaei, M. M.; Nazari, E. Rapid and Mild Sulfonylation of Aromatic Compounds with Sulfonic Acids via Mixed Anhydrides Using $\mathrm{Tf}_{2} \mathrm{O}$. Tetrahedron Lett. 2007, 48, 6805-6808. (i) Yao, B.; Zhang, Y. Sulfonylation of arenes with sulfonamides. Tetrahedron Lett. 2008, 49, 5385-5388. (j) Yang, Y.; Chen, Z.; Rao, Y. The Synthesis of Diarylsulfones with Simple Arenes and $\mathrm{K}_{2} \mathrm{~S}_{2} \mathrm{O}_{8}$ through Double $\mathrm{C}-\mathrm{S}$ Bond Formation. Chem. Commun. 2014, 50, 15037-15040. (k) Zhang, Z.; Wang, S.; Zhang, Y.; Zhang, G. Regiospecific Cleavage of S-N Bonds in Sulfonyl Azides: Sulfonyl Donors. J. Org. Chem. 2019, 84, 3919-3926. (10) (a) Bonazaba Milandou, L. J. C.; Carreyre, H.; Alazet, S.; Greco, G.; Martin-Mingot, A.; Nkounkou Loumpangou, C.; Ouamba, J.-M.; Bouazza, F.; Billard, T.; Thibaudeau, S. Superacid-Catalyzed Trifluoromethylthiolation of Aromatic Amines. Angew. Chem., Int. Ed. 2017, 56, 169-172. (b) Mamontov, A.; Martin-Mingot, A.; Métayer, B.; Karam, O.; Zunino, F.; Bouazza, F.; Thibaudeau, S. Complementary Site-Selective Halogenation of Nitrogen-Containing (Hetero)Aromatics with Superacids. Chem. - Eur. J. 2020, 26, 10411-10416. (c) Bhuma, N.; Lebedel, L.; Yamashita, H.; Shimizu, Y.; Abada, Z.; Ardá, A.; Désiré, J.; Michelet, B.; Martin-Mingot, A.; Abou-Hassan, A.; Takumi, M.; Marrot, J.; Jiménez-Barbero, J.; Nagaki, A.; Blériot, Y.; Thibaudeau, S. Insight into the Ferrier Rearrangement by Combining Flash Chemistry and Superacids. Angew. Chem., Int. Ed. 2021, 60, 2036-2041.

(11) Olah, G. A.; Prakash, K. S.; Molnar, A.; Sommer, J. Superacid Chemistry, 2nd ed.; Wiley: New York, 2009.

(12) (a) Olah, G. A.; Klumpp, D. A. Superelectrophiles and Their Chemistry; Wiley: New York, 2008. (b) Naredla, R. R.; Klumpp, D. A. Contemporary Carbocation Chemistry: Applications in Organic Synthesis. Chem. Rev. 2013, 113, 6905-6948.

(13) $m$-Methylacetanilide was observed in some cases in the crude reaction mixture but was never isolated. Such isomerization is a known drawback of Friedel-Crafts alkylations. See: Olah, G. A.; Farooq, O.; Farnia, S. M. F.; Olah, J. A. Boron, Aluminum, and Gallium Tris(trifluoromethanesulfonate) (Triflate): Effective New Friedel-Crafts Catalysts. J. Am. Chem. Soc. 1988, 110, 2560-2565.

(14) For a similar rearrangement that was recently observed, see: Michelet, B.; Castelli, U.; Appert, E.; Boucher, M.; Vitse, K.; Marrot, J.; Guillard, J.; Martin-Mingot, A.; Thibaudeau, S. Access to Optically 
Pure Benzosultams by Superelectrophilic Activation. Org. Lett. 2020, 22, 4944-4948.

(15) (a) Dong, J.; Krasnova, L.; Finn, M. G.; Sharpless, B. Sulfur(VI) Fluoride Exchange (SuFEx): Another Good Reaction for Click Chemistry. Angew. Chem., Int. Ed. 2014, 53, 9430-9448. (b) Barrow, A. S.; Smedley, C. J.; Zheng, Q.; Li, S.; Dong, J.; Moses, J. E. The growing applications of SuFEx click chemistry. Chem. Soc. Rev. 2019, $48,4731-4758$

(16) Bandini, M.; Eichholzer, A. Catalytic Functionalization of Indoles in a New Dimension. Angew. Chem., Int. Ed. 2009, 48, 96089644.

(17) As far as we are aware, this product is actually the first example of direct para-sulfonylation of a phenylalanine derivative.

(18) Olah, G. A.; Ku, A. T.; Olah, J. A. Protonation and Cleavage Reactions of Alkyl- and Aryl-sulfonic Acids and Sulfinic Acids and Alkyl Sulfonates and Sulfinates in Fluorosulfuric Acid-Antimony Pentafluoride Solution. J. Org. Chem. 1970, 35, 3908-3912.

(19) Dhakal, B.; Bohé, L.; Crich, D. Trifluoromethanesulfonate Anion as Nucleophile in Organic Chemistry. J. Org. Chem. 2017, 82, 9263-9269.

(20) The arenesulfonyl fluoride is most likely in a protonated form in $\mathrm{HF} / \mathrm{SbF}_{5}$, as suggested by the in situ ${ }^{13} \mathrm{C}$ and ${ }^{19} \mathrm{~F}$ NMR analyses (see the SI).

(21) Benzenesulfonyl fluoride is protonated on the oxygen atom in $\mathrm{FSO}_{3} \mathrm{H} / \mathrm{SbF}_{5} / \mathrm{SO}_{2} \mathrm{ClF}$ superacidic solution and remains stable up to room temperature. See: Olah, G. A.; Ku, A. T.; Olah, J. A. Sulfonyl Halide-Antimony Pentafluoride Complexes and Study of Protonation and Cleavage of Sulfonyl Halides in Fluorosulfuric Acid-Antimony Pentafluoride-Sulfuryl Chloride Fluoride Solution. J. Org. Chem. 1970, 35, 3925-3928.

(22) Börgel, J.; Ritter, T. Late-Stage Functionalization. Chem. 2020, $6,1877-1887$. 